\title{
Fabrication of Miniature Antimony pH Electrodes -Short Communication-
}

\author{
by \\ H. J. SANDHAM* and H. ONOSE**
}

A need exists for fine $\mathrm{pH}$ electrodes capable of measuring $\mathrm{pH} 1$ ) in pits and fissures in the occlusal surfaces of teeth, 2) in crevices around the margins of restorations, 3 ) in plaque on smooth surfaces of teeth with minimal disturbance, and 4) in the teeth of experimental animals. Although small electrodes have been constructed previously by a number of workers, a combination of small size and durability has been difficult to obtain. Cast antimony electrodes (KLEINBERG, 1958) and glass electrodes (Charlton, Fitzgerald and Keyes, 1971) with small tips have been fabricated, but lack the necessary durability for routine use in humans when the diameters of the tips are less than $100 \mu \mathrm{m}$. More durable electrodes made by electroplating antimony onto metals such as copper or brass (DE JAGER and THERON, 1963; BowEN, 1969) have had antimony coatings that were too thick to permit the formation of extremely fine tips.

During preliminary experiments to find a method of making finer and more durable electrodes, we found that fine sharpened platinum or steel wires could be thinly coated with antimony simply by dipping them for an instant into molten antimony. The resulting electrodes had tips with a diameter between 20 and $50 \mu \mathrm{m}$. Although the coating process was easier with platinum wires, the resulting electrodes were too easily bent during intraoral use. Consequently, stainless steel wire was used to provide rigidity.

The microelectrodes were fabricated by sharpening the end of a piece of $142 \mu \mathrm{m}$ diameter stainless steel spring wire, either by rubbing on fine emery paper or by electropolishing. The wire was then cut to a length of $3-5 \mathrm{~mm}$ and joined to the bared end of a $12 \mathrm{~cm}$ length of copper bell wire by wrapping them together with 36 gauge copper wire so that the steel wire pojected 1.5 to $2 \mathrm{~mm}$ beyond the end of the bell wire (Fig. 1). The end of the electrode was then dipped instantaneously into molten antimony so that a thin layer of antimony coated the steel wire and part of the 36 gauge copper wire wrapping. The dipping process frequently had to be repeated several times before a satisfactory coating was obtained. The temperature of the molten antimony was critical. If the temperature of the antimony was too low, the thickness of the coating was too great. On the other hand, temperatures that were too high caused the antimony to form as beads on the surface of the steel.

The tip of the electrode was then covered with a small amount of wax and the remainder of the electrode was insulated with a coat of 5-minute epoxy resin. Care

* H. J. Sandham: Dept. of Preventive Dentistry, Faculty of Dentistry, University of Toronto, Canada.

** 小野瀬英雄: Dept. of Operative Dentistry, Nihon University School of Dentistry, Tokyo. 


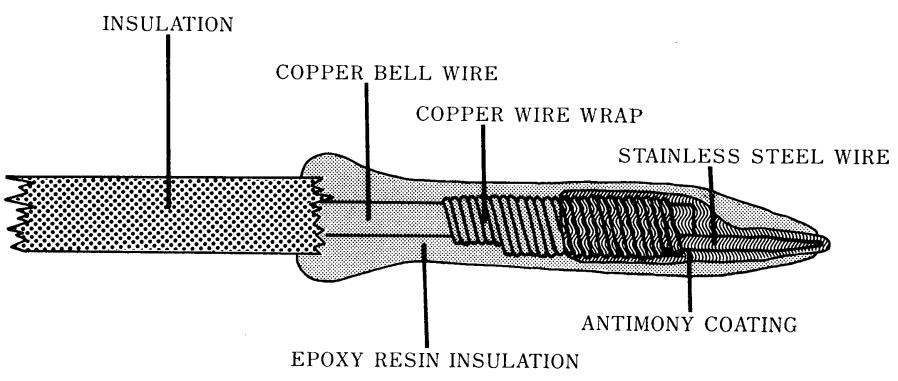

Fig. 1. Diagrammatic representation of the miniature antimony electrode

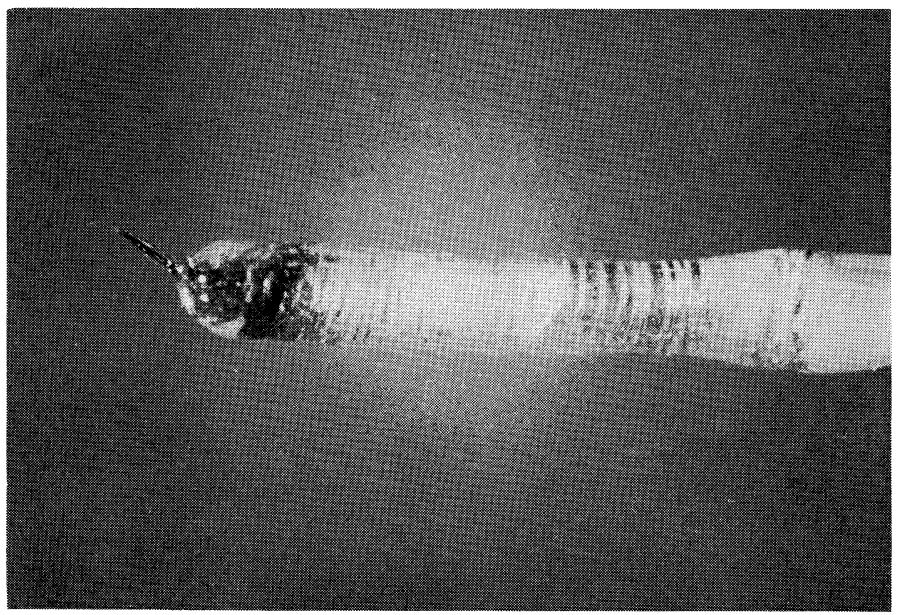

Fig. 2. Photograph of miniature antimony electrode

was taken to minimize the thickness of the epoxy resin at the tip of the electrode by holding the electrode in a vertical position so that excess epoxy resin flowed away from the tip. The epoxy resin was built up to a greater thickness over the remainder of the electrode extended to cover the end of the insulation covering the bell wire. The finished electrode is shown in Figure 2.

For use, the electrode was connected with a $\mathrm{pH}$ meter capable of providing readings in millivolts. The circuit was completed with a potassium chloride salt bridge leading to a reference electrode and a salt bridge. The end of the salt bridge was similar to that previously described by KLEINBERG (1958), made of glass tubing with porous pipe clay in the end.

When the response of the miniature electrodes in a series of standard $\mathrm{pH}$ buffer solutions between $\mathrm{pH} 4.0$ and 9.0 was compared to that obtained from cast antimony electrodes fabricated by the method described by KLEINBERG (1958), stable, reproducible readings were obtained within 2 seconds with both types of electrodes, and the relation between $\mathrm{pH}$ and millivolt readings was the same. 
Table 1. $\mathrm{pH}$ readings five minutes after sucrose application

\begin{tabular}{|c|c|c|c|c|c|}
\hline \multirow[b]{2}{*}{ Subject } & \multirow[b]{2}{*}{ Tooth } & \multirow[b]{2}{*}{ Location } & \multicolumn{2}{|c|}{$\mathrm{pH}$ readings with: } & \multirow[b]{2}{*}{ Difference } \\
\hline & & & $\begin{array}{l}\text { Large } \\
\text { electrode }\end{array}$ & $\begin{array}{c}\text { Small } \\
\text { electrode }\end{array}$ & \\
\hline & Caries-r & individuals: & & & \\
\hline \multirow[t]{2}{*}{ A } & $\overline{6}$ & central pit & 6.7 & 6.3 & -0.4 \\
\hline & $\overline{6 !}$ & central pit & 6.9 & 6.7 & -0.2 \\
\hline \multirow[t]{2}{*}{ B } & 6 & central pit & 7.0 & 6.9 & -0.1 \\
\hline & $\overline{7}$ & central pit & 6.9 & 6.6 & -0.3 \\
\hline \multirow[t]{2}{*}{$\mathrm{C}$} & $\overline{7}$ & central pit & 6.9 & 6.5 & -0.4 \\
\hline & $\overline{61}$ & mesial pit & 6.7 & 6.2 & -0.5 \\
\hline \multirow[t]{2}{*}{$\mathrm{D}$} & $\overline{6]}$ & mesial pit & 7.0 & 6.5 & -0.5 \\
\hline & $\overline{7 \mid}$ & central pit & 6.8 & 6.5 & -0.3 \\
\hline \multirow[t]{3}{*}{$\mathbf{E}$} & $\overline{6}$ & mesial pit & 6.8 & 6.6 & -0.2 \\
\hline & $\sqrt{6}$ & central pit & 6.9 & 6.5 & -0.4 \\
\hline & Caries-s & le individua & & & \\
\hline \multirow[t]{2}{*}{$\mathrm{F}$} & $\overline{6}$ & central pit & 5.5 & 5.4 & -0.1 \\
\hline & $\overline{61}$ & mesial pit & 5.3 & 5.0 & -0.3 \\
\hline \multirow[t]{2}{*}{ G } & $\overline{7 \mid}$ & central pit & 5.7 & 5.3 & -0.4 \\
\hline & $\overline{71}$ & central pit & 5.5 & 5.3 & -0.2 \\
\hline \multirow[t]{2}{*}{$\mathrm{H}$} & $\overline{61}$ & central pit & 5.4 & 5.0 & -0.4 \\
\hline & $\overline{7}$ & central pit & 5.5 & 5.4 & -0.1 \\
\hline \multirow[t]{2}{*}{ I } & $\sqrt{6}$ & distal pit & 5.7 & 5.5 & -0.2 \\
\hline & $\overline{6 !}$ & mesial pit & 5.3 & 5.0 & -0.3 \\
\hline \multirow[t]{2}{*}{$\mathbf{J}$} & $\overline{7}$ & central pit & 5.5 & 5.1 & -0.4 \\
\hline & $\overline{6}$ & central pit & 5.7 & 5.3 & -0.4 \\
\hline
\end{tabular}

Testing of the miniature electrodes in humans was carried out by comparing their performance with cast antimony electrodes having a tip diameter of approximately $200 \mu \mathrm{m}$. The objective of the testing was to determine whether the deeper penetration of the miniature electrodes into the pits and fissures would produce lower $\mathrm{pH}$ readings than with the larger cast electrodes. Readings were made of the $\mathrm{pH}$ of plaque in pits and fissures of seven children approximately 5 minutes after a 10 percent sucrose solution was applied. The children had not been instructed to refrain from brushing their teeth. Saliva was excluded by isolating the teeth with cotton rolls from the time that the sucrose was applied until the readings were completed. In three of the subjects, repeated readings were taken over a period of twenty minutes, with each of the electrodes being used alternately, with essentially similar results. Typical data for ten children are shown in Table 1.

In five children with a very low rate of caries activity, all readings were obtained from the pits of lower posterior teeth. In every case, the $\mathrm{pH}$ readings obtained with the small electrode were lower than those obtained with the larger electrode. Similar results were obtained from the pits in five children with a high caries rate and from the other five children examined. We interpret these clinical findings to mean that the concentration of acid was greater and deeper in the pits and fissures than it was at the surface, and that the miniature electrode was able to penetrate deeper into these acidic areas than was the larger electrode. Although the tips of the miniature electrodes are small and slender, it cannot necessarily be expected that they reached the bottom of 
the pits or fissures. Pits and fissures in human teeth are known to frequently contain constrictions as narrow as $10 \mu \mathrm{m}$ and are frequently jug-shaped or exceedingly tortuous (GILlings and BuONOCORE, 1961); construction of electrodes capable of reaching to the bottom of pits and fissures would appear to be very difficult. However, the miniature electrodes described here, because they can penetrate deeper into the pits and fissures than previously reported electrodes, probably detect the acid concentrations in these areas more accurately.

Recently, we have found that the electrodes are more easily constructed when tungsten carbide is used as a core instead of stainless steel. A tungsten carbide rod $250 \mu \mathrm{m} \times 3 \mathrm{~cm}$ (special order, Toshiba Tangaroy Company, Tokyo) is sharpened with a diamond stone in a dental handpiece and fine emery paper. It is then briefly exposed to $5 \mathrm{~N} \mathrm{HCl}$ prior to coating with antimony.

\section{References}

Bowen, W. H.: The monitoring of acid production in dental plaque in monkeys; Brit. dent. J., 126, 506-508, (1969).

Charlton, G., Fitzgerald, R. J. and Keyes, P. H.: Determination of saliva and dental plaque $\mathrm{pH}$ in hamsters with glass microelectrodes; Archs oral Biol., 16, 649-654, (1971).

De JAGER, C. L. and Theron, J. J.: An antimony-brass electrode for intra-oral pH determinations; J. dent. Ass. S. Afr., 18, 70-74, (1963).

Gillings, B. and Buonocore, M.: Thickness of enamel at the base of pits and fissures in human molars and bicuspids; J. dent. Res., 40, 119-133, (1961).

KLEINBERG, I.: The construction and evaluation of modified types of antimony micro-electrodes for intraoral use; Brit. dent. J., 104, 197-204, (1958). 